\title{
Economic Exchange during Hyperinflation
}

\section{Alessandra Casella}

University of California, Berkeley

\section{Jonathan S. Feinstein}

Stanford University

\begin{abstract}
Historical evidence indicates that hyperinflations can disrupt individuals' normal trading patterns and impede the orderly functioning of markets. To explore these issues, we construct a theoretical model of hyperinflation that focuses on individuals and their process of economic exchange. In our model buyers must carry cash while shopping, and some transactions take place in a decentralized setting in which buyer and seller negotiate over the terms of trade of an indivisible good. Since buyers face the constant threat of incoming younger (hence richer) customers, their bargaining position is weakened by inflation, allowing sellers to extract a higher real price. However, we show that higher inflation also reduces buyers' search, increasing sellers' wait for customers. As a result, the volume of transactions concluded in the decentralized sector falls. At high enough rates of inflation, all agents suffer a welfare loss.
\end{abstract}

\section{Introduction}

Since Cagan (1956), economic analyses of hyperinflations have focused attention on aggregate time-series data, especially exploding price levels and money stocks, lost output, and depreciating exchange rates. Work on the German hyperinflation of the twenties provides a

We thank Olivier Blanchard, Peter Diamond, Rudi Dornbusch, Stanley Fischer, Bob Gibbons, the referee, and the editor of this Journal for helpful comments. Alessandra Casella thanks the Sloan Foundation and Consiglio Nazionale delle Ricerche for financial assistance. 
good example of this approach; see, among others, the econometric studies of money demand by Sargent and Wallace (1973), Frenkel (1977), Salemi and Sargent (1979), and Christiano (1987) and the tests for speculative price bubbles presented by Flood and Garber (1980), Burmeister and Wall (1982, 1987), and Casella (1989).

If we compare these studies with historical accounts of the German experience, the difference in focus is striking. Whereas economists concentrate on aggregate performance measures, historians emphasize the hyperinflation's disruptive impact on individuals and on their socioeconomic relationships. Previously stable trading connections were severed, transactions patterns were altered, and normally wellfunctioning markets collapsed (see Feldman 1977, 1989; Feldman et al. 1984; Kunz 1986; Moeller 1986).

In this paper we present an attempt to bridge the gap between the historical literature and economic analysis. We construct a formal economic model of hyperinflation that centers on individual trading patterns and on the exchange process, and we explore the implications of this model for relative prices, market structure, and social welfare. Our results are consistent with historical evidence, but our model naturally addresses only a small part of a larger set of issues. Our main purpose is to show, by example, the usefulness of reexamining hyperinflations at a more detailed analytic level.

Our approach depends on two main assumptions, both of which have been motivated by our reading of life experiences during the German inflation. First, we assume that domestic money is required for all transactions. Two pieces of evidence support this assumption: the legal restriction that prohibited the holding of foreign currencies and the general unwillingness to resort to barter up until the very last months prior to stabilization.

Second, we construct our model so as to emphasize time and the importance of converting depreciating nominal accounts into real goods as quickly as possible. Many anecdotes reveal how important time became during the German inflation:

Almost daily at the ten o'clock break I used to see the teachers trooping down into the [school's] playground where their friends and relatives were waiting, into whose hands they thrust the money that they'd just received so that it could be spent before the prices went up. [Dorothy Haenkel in Guttmann and Meehan (1975, p. 80)]

At eleven o'clock in the morning a siren sounded and everybody gathered in the factory forecourt where a fiveton lorry was drawn up loaded brimful with paper money. The chief cashier and his assistants climbed up on top. 
They read out names and just threw out bundles of notes. As soon as you had caught one you made a dash for the nearest shop and bought just anything that was going. [Willy Derkow in Guttmann and Meehan (1975, pp. 5758)]

We incorporate these two assumptions into a simple model of an economy populated by overlapping generations of agents and consisting of two sectors labeled red and blue. We focus mainly on the red sector, which is a decentralized market in which buyers must search for an available seller. When a buyer and seller meet, they bargain over the terms of trade of the indivisible red good, and we model this bargaining as a modified version of Rubinstein's (1982) game. As we shall see, the buyer's need to convert money into the red good as quickly as possible strongly affects the outcome of the bargain and has further repercussions on search behavior and red market structure. The blue sector, in contrast to the red, is centralized, consisting of a perfectly competitive market in which all sellers charge the same equilibrium price for the blue good. In accordance with our first assumption above, all transactions on both markets require cash. Finally, additional money is injected into the economy each period; hence nominal prices are rising on both markets.

Our analysis of this model explores three issues, in each case leading to results that seem consistent with available evidence. The first issue is the effect of inflation on relative prices and relative incomes. A buyer in the decentralized sector must carry cash while searching for an available seller and negotiating the terms of trade. Hence he faces the continual depreciation of his real money holdings and, most important, the pressing competition of new buyers, who enter the market with increasing amounts of nominal money. The buyer's weakening position over time stands in sharp contrast to the stable position of the seller, who is able to hold his nondepreciating good until successfully completing a transaction. This asymmetry between the two agents translates into an increase in the bargaining power of the seller and a redistribution of the trading surplus in his favor: the relative price of the good sold in the decentralized sector and the seller's real income are higher the higher is the economy's inflation rate. This conclusion appears to capture, and rationalize, anecdotal evidence: "The frantic urge to buy, combined with the reluctance of producers and owners of goods to sell for depreciating marks, naturally drove prices up" (Guttmann and Meehan 1975, p. 29).

The second issue we explore is the impact of inflation on agents' welfare. In accordance with the partial equilibrium intuition discussed above, we find that sellers in the decentralized sector benefit 
from increased inflation over a wide range of inflation rates, while buyers suffer. Hence in our model there is no inflation rate that is unequivocally Pareto dominant, excluding lump-sum transfers. However, we also find that at sufficiently high inflation rates, both buyers' and sellers' expected utilities fall. The intuition is simple: the buyers will continue their search as long as they have a positive probability of engaging in a successful transaction. But inflation is eroding their real balances, and eventually they might become so "poor" that no seller could be induced to consider them as potential customers. At this point, they would leave the market. At higher inflation rates the number of periods allowed for search will be lower, and the average number of buyers per store smaller. This will in turn negatively affect the sellers, who will have to wait longer before being contacted by a suitable customer. In a sense, sellers suffer from a lack of coordination; each individually prefers not to talk to "older" buyers and disregards the impact of his decision on the group as a whole. Again, this result appears to coincide with available evidence: "Shops remained empty, and their suppliers, unable for this reason to get rid of their wares, reduced production" (Guttmann and Meehan 1975, p. 75).

Finally, we calculate the velocity of circulation of money in the economy. At higher inflation rates, as buyers leave the decentralized market at earlier dates, the average time during which they hold currency is shortened, and the velocity of circulation is increased. Any new injection of money will then have a larger effect on the price level. This is, of course, the traditional assumption of hyperinflation models, here derived endogenously.

Our results bear comparison with the large and diverse literature on inflation and, more specifically, with previous analyses studying the effect of inflation on trade, when money is required for transactions. Originating with Friedman (1969), this literature sees inflation as a distortionary tax on money balances. In a world in which lumpsum taxes are available, the optimal rate of nominal price increase equals the negative of the real interest rate: the cost of holding money is then equalized to the social cost of supplying money, that is, to zero. Bewley (1980) and Townsend (1980) prove formally that if agents are infinitely lived and have a common discount rate, the required price deflation entails an infinite money stock. Government intervention in the form of lump-sum taxes on money is necessary for Friedman's result. The initial intuition is applied to more complex models by Jovanovic (1982), Rotemberg (1984), and Romer (1986), among others, without altering the conclusion. Lucas and Stokey (1983) and Lucas (1986) enrich the framework to a world in which some goods are purchased with money and others with credit. Here inflation distorts society's allocation of resources away from the cash-in-advance sector by changing the relative cost of the two goods, and Friedman's 
rule is again optimal. In our model, all transactions require cash and Friedman's result does not hold. However, the logic of these latter works does carry over to our economy, in a modified form: when economic sectors differ in their exchange technologies, inflation may affect them differently, distorting relative prices. The papers by Lucas and by Lucas and Stokey and our analysis are all examples of this general effect.

Finally, the model presented here represents a natural extension of the work of Diamond (1982, 1984) and Diamond and Yellin (1984, 1985), who study search and decentralized exchange. The important difference is the introduction of strategic bargaining as a way to determine how the surplus from trade will be shared. Given inflation and the cash-in-advance constraint, this feature endogenizes the maximum number of periods allowed for search. It is then possible to follow, in a relatively simple way, the distribution of money holdings in the economy and therefore to completely characterize the general equilibrium solution, even in the presence of inflation.

The paper is organized as follows. Section II presents the model. Then Sections III-VII analyze the simplest cases of the model. Section III explicitly derives the solution of the bargaining game for specific ranges of inflation rates that lead to a simplified analysis; Section IV describes in detail the matching process through which buyers and sellers meet; Section V derives the inflation rate, as a function of the increase in the money supply and the (endogenous) circulation of agents in the economy; and Sections VI and VII characterize the complete solution of the model. Finally, Section VIII extends the previous results to the general case, and Section IX presents conclusions.

\section{The Model}

The economy is composed of two sectors. In the blue market a divisible good is sold competitively: this market is centralized, and equilibrium prices are posted and adhered to by all traders. In contrast, in the red market the exchange of a storable, indivisible commodity is decentralized: individual buyers and sellers bargain over terms of trade prior to transaction.

There is no production, and each period $n_{b}$ blue agents and $n_{r}$ red agents are born with an endowment of one unit of their respective good. Their utility functions are

$$
\begin{aligned}
& U_{r}=\delta^{s} q_{b}, \\
& U_{b}= \begin{cases}\delta^{s} q_{b} & \text { if the red good has been purchased } \\
\delta^{s} q_{b}-A & \text { otherwise, }\end{cases}
\end{aligned}
$$


where $\delta(<1)$ is the common discount factor, $q_{b}$ is the consumption of the blue good, and $s$ is the number of periods since birth when this consumption takes place.

Everybody desires the blue good, while the red good is valued by only the blue consumers, who suffer a large disutility, $A$, if they are unable to purchase it. We assume that $A$ is large enough to make them willing to pay any feasible price for the red commodity and to remain in the red market as long as there is any positive probability of a successful transaction. ${ }^{1}$

Agents exit the economy after consumption; hence the model is a modified overlapping generations framework in which the number of periods till death is endogenous.

Transactions in the red market are characterized by a matching process, through which traders meet, and a bargaining game. We assume that identical red sellers sit in their stores waiting for blue buyers who choose randomly and independently where to shop. When customers enter a store, the seller decides which of them, if any, he wants to address and starts bargaining with him over the price of the red good. Since buyers choose the stores independently, each has a positive probability of not being alone and of not being selected by the seller. If this occurs, the neglected customer can either wait, look for another store, or leave the red market altogether. ${ }^{2}$

The bargaining is described by a modification of Rubinstein's original game with complete information. The buyer and the red seller negotiate over the terms of trade of the red (indivisible) good. The negotiation proceeds in a series of offers and counteroffers; the seller quotes the first price, and the buyer can accept it or reject it. If he rejects it, he makes a counteroffer. Whenever the red seller moves, he has three options: he can continue to bargain with the original buyer, choose a new customer (if a new customer shows up), or refuse to make his offer and end the current bargaining even if no agreement has been reached and no new customer has arrived. ${ }^{3}$

\footnotetext{
${ }^{1}$ A possible extension of the model would be to see how the equilibrium solution reacts to changes in $A$. As the probability of engaging in a successful transaction in the red market becomes small, for certain values of $A$ it might be optimal for a blue consumer, ceteris paribus, to avoid the effort of trying to purchase the red good. As this is true for all-identical-blue agents, the probability of success in the red market goes to one. Hence, equilibrium requires a mixed strategy.

${ }^{2}$ We might imagine that if more than one buyer arrived at his store, the seller could hold an auction, selling the good for the highest price. If the auction is sealed-bid, he will extract (i) all the income of one member of the youngest generation of buyers present if more than one such buyer arrives or (ii) a price equal to the income of the second-youngest buyer. Our bargaining model continues to apply when only one buyer shows up (which occurs with positive probability), with an appropriate modification of the expected off-equilibrium price.

${ }^{3}$ Both these possibilities are available but irrelevant in Rubinstein's original game with identical players. In our model, inflation creates differences between the buyers and therefore lends importance to these otherwise negligible moves.
} 
It is assumed that goods can be bought only with money. There is no credit system, and a cash-in-advance constraint forces consumers to hold their nominal balances while shopping. In fact, agents' endowments are such that a nonmonetary barter equilibrium could be supported; hence we must assume the transactions role of money, rather than derive it endogenously as in classic overlapping generations models.

A source of money, and inflation, is a supposedly benign government agency, called "the bank," whose sole activity is to multiply the money holdings of its clients and therefore the money circulating in the economy. For simplicity, we assume that the blue consumers go to the bank on the way to the red market, but any other configuration (i.e., both red and blue, or only the red, go to the bank) would leave the substance of our analysis unaffected. Indeed, the same results could be obtained by having the government directly buying blue goods with newly printed money or by making any assumption that would capture the progressive increase in the nominal money holdings of successive generations. The nominal price on the blue market, $p_{b t}$, goes up steadily because the same total endowment is traded each period for an always increasing money stock.

In equilibrium, the life of a blue consumer is described by the following succession of moves. At time $t$, he is born with one unit of the blue good, which he immediately sells on the competitive market, earning the nominal price $p_{b t}$. At time $t+1$, he goes to the red market and, on the way, stops at the bank, where his money holdings are increased by a factor of $\alpha_{0}$. With $\alpha_{0} p_{b t}$ in cash, he enters a red seller's store and, if chosen, starts bargaining. At time $t+2$, if the bargaining has been successful, he returns to the blue market, where he spends all his remaining money. If he was not chosen by the red seller in period $t+1$, he goes to another red store. The blue's search for a willing seller continues until either he succeeds in buying the red good or his money holdings have so depreciated that no seller would trade with him. In all cases, his final move is to spend all the money he has left in the blue market.

As for the red consumer, at time $t$ he is born with one indivisible red good and stays in his store waiting for a customer. If a single buyer enters, the seller makes him an offer, unless he considers him too poor. If more than one buyer enters the store, he addresses the one who can afford to spend the most or, if all are identical, he chooses one randomly (unless all are too poor). At time $t+1$, if he made an offer to a buyer at time $t$, the transaction is completed (in equilibrium) and he goes to the blue market to spend the proceeds. Otherwise he again waits for a suitable customer: he has to remain in his store as long as needed to sell his good and earn the money that he will finally spend in the blue market. 
As we shall see, the economy is completely characterized by three fundamental parameters: $\delta$, the discount rate; $n_{b} / n_{r}$, the ratio of blue to red consumers born each period; and $\alpha_{0}$, the multiplicative factor describing the intervention of the bank. In the following sections, we compute steady-state equilibria, as functions of these parameters, and compare relative prices and expected utilities.

\section{The Bargaining Game}

With inflation eroding the real value of his money holdings, a blue buyer cannot continue to search indefinitely for a well-disposed seller in the red market: if he has been unsuccessful (has not been chosen by any of the sellers he has approached) for too long, his real wealth might have become so low that any seller would rather wait for future potential customers than bargain with him, even if he is the only customer in the store.

Of course, the critical number of periods allowed for search depends on the inflation rate, and we can define different "regimes" as ranges of inflation rates corresponding to a specific number of periods that can at most be devoted to search. Within each of these regimes, the red seller is willing to bargain only with customers whose "age" in the market is below that critical threshold. ${ }^{4}$

To keep the exposition simple and the equations tractable, we start by concentrating on a specific example: a range of inflation rates such that the red sellers are willing to bargain at most with buyers who have just arrived in the market (young) or have gone through a single unlucky search (old). We call this the two-generation regime. We then explicitly derive the equilibrium results and study the transition to the one-generation regime, with its welfare implications. The final section of the paper presents the solution for the general case.

\section{Bargaining Equilibrium: The Two-Generation Regime}

The bargaining game is complicated by the presence in the market of buyers of different ages and by the uncertainty created by the matching process. When a buyer enters a store, neither he nor the seller knows whether any new customer, young or old, will arrive in the near future. In addition, the original buyer himself can be either young or old.

The simplifying feature of the game is its preserved stationarity: nothing is modified over time, and the value of bargaining with a

\footnotetext{
${ }^{4}$ In the model we discuss, the length of the time unit, the bargaining period, is exogenous and fixed. A nontrivial improvement would be to have it determined endogenously. In that case, it would clearly be affected by the inflation rate, with seller and buyer presumably having contrasting objectives.
} 
specific buyer (young or old) is the same in any period. It is this fundamental property that characterizes the game.

A few observations will help us derive the solution.

1. Since the seller is not willing to bargain with buyers who have been in the market more than two periods (very old), he will always stop negotiating with the original customer if no agreement has been reached before period 3 . However, he has to give the customer the right to a counteroffer in period 2, regardless of his age or of the possible flow of competing buyers.

2. In period 3, the seller will switch to a young buyer, if one enters the store, or to an old buyer, if at least one arrives and no young buyers are present at the time (see the proof in Casella and Feinstein [1987]). If nobody enters the store, the seller will wait. Therefore, the ex ante value of the game to the seller in period 3 in the twogeneration regime, $x_{2}$, is

$$
x_{2}=v_{y 2} p_{y 2}+v_{o 2} p_{o 2}+v_{n 2} \delta x_{2},
$$

where $v_{i 2}$ is the probability of addressing a customer of type $i(i=y, o)$ in the two-generation regime, $v_{n 2}$ is the probability of having no new customers, and $p_{i 2}$ is the real price of the good when sold to a customer of type $i$.

3. Let us define as $I_{\imath}$ the real money balances of a buyer of type $i$ in period 1 and as $\pi$ the rate of nominal price increase, per period, in the blue market (which will later be determined endogenously). When we exploit stationarity, the sequence of alternating offers that would take place off equilibrium, and that determines the equilibrium price, can be analyzed in the elegant diagram proposed by Sutton (1986).

\begin{tabular}{llcc}
\hline \hline Period & Offer Sequence & Seller's Share & Buyer's Share \\
\hline 1 & Seller to buyer & $\min \left\{I_{2}, I_{2}-\delta\left[\left(I_{2} / \alpha\right)-\delta x_{2}\right]\right\}$ & $\max \left\{\delta\left[\left(I_{2} / \alpha\right)-\delta x_{2}\right], 0\right\}$ \\
2 & Buyer to seller & $\delta x_{2}$ & $\max \left[\left(I_{2} / \alpha\right)-\delta x_{2}, 0\right]$ \\
3 & Seller to buyer & $x_{2}$ & $\cdots$ \\
\hline
\end{tabular}

Since the value of the game to the seller in period 3 is $x_{2}$, if no agreement had been reached in the first period, the buyer, moving at time 2, should offer at least $\delta x_{2}$, keeping for himself $\left(I_{i} / \alpha\right)-\delta x_{2}$, if positive, or zero (where $\alpha \equiv 1+\pi$ ). Anticipating this, the seller in period 1 will quote as a price $I_{i}-\delta\left[\left(I_{i} / \alpha\right)-\delta x_{2}\right]$, if less than $I_{i}$, or $I_{i}$, leaving to the buyer $\delta\left[\left(I_{\imath} / \alpha\right)-\delta x_{2}\right]$ or zero. This characterizes a perfect equilibrium in which trade takes place in the first period and

$$
p_{i 2}=\min \left[I_{i}, I_{i}\left(1-\frac{\delta}{\alpha}\right)+\delta^{2} x_{2}\right] \text {, }
$$

where $x_{2}$ is defined by equation (1) and $\alpha \equiv 1+\pi$. 
Equations (2) and (1) establish that this price is nondecreasing in inflation. As expected, the combination of inflation with a cash-inadvance constraint weakens the bargaining position of the buyer. In addition, since we know that $I_{y}=\alpha I_{o}$ (by the definition of young and old), equation (2) implies that the young buyers always pay a higher price than the old, justifying the preference of the seller, but a smaller share of their wealth. As expected, successful search has a positive payoff.

The condition that restricts the seller to bargaining with only two generations of buyers determines the range of inflation rates underlying the equilibrium described by equations (1) and (2). It must be true that if every other store sells to young and old customers, it is not profitable for a single seller to deviate and either expand his trade to the very old or restrict it to only the young. This implies

$$
\begin{aligned}
& p_{v o 2} \leq \delta x_{2}, \\
& p_{o 2} \geq \delta x_{1},
\end{aligned}
$$

where $\delta x_{2}$ is, as before, the value to the seller of waiting another period, when his only customer is a very old buyer and the seller contemplates bargaining with young and old only. Similarly, $\delta x_{1}$ is the value of waiting when the one available buyer is old and the seller has the alternative of addressing only young customers.

The very old buyer would rather exchange his whole money holdings for the red good than abandon the hope of purchasing it and incur a large disutility. Therefore, the two-generation regime can be an equilibrium only if

$$
I_{v o} \leq \delta x_{2},
$$

with equation (5) holding with equality at the inflation rate at which the transition to the two-generation regime takes place. Recalling that $I_{v o}=I_{o} / \alpha$ and

$$
p_{o 2}=\min \left[I_{o}, I_{o}\left(1-\frac{\delta}{\alpha}\right)+\delta^{2} x_{2}\right]
$$

and substituting $(5)$ in $\left(2^{\prime}\right)$, we conclude that

$$
p_{o 2}=I_{o}
$$

The lower bound of the range of inflation rates for which the twogeneration regime is an equilibrium is exactly the rate at which, in the present regime, the seller will extract the whole surplus from the old 
buyers $\left(\pi_{o}\right){ }^{5}$ Taking this into account, we can obtain the equation defining $\pi_{o}$ from (1) and (2): $\pi_{o}$ solves:

$$
\begin{aligned}
& v_{y 2}\left(1+\pi_{o}\right)^{2}+\left(1+\pi_{o}\right)\left(v_{o 2}-\delta v_{y 2}\right) \\
& -\left[v_{o 2}+v_{y 2}(1-\delta)+\frac{1-\delta}{\delta}\right]=0 .
\end{aligned}
$$

Equation (4) will give us the upper bound of the relevant range of inflation rates. When one seller deviates and trades with young customers only, the ex ante value of the bargaining game from his point of view is

$$
x_{1}=v_{y 2} p_{y 1}+\left(1-v_{y 2}\right) \delta x_{1},
$$

and, when we repeat once more the usual logical steps, the price set to the young buyers is

$$
p_{y 1}=\min \left[I_{y}, I_{y}\left(1-\frac{\delta}{\alpha}\right)+\delta^{2} x_{1}\right]
$$

which implies

$$
x_{1}=\min \left\{I_{y} \frac{v_{y 2}}{1-\delta\left(1-v_{y 2}\right)}, I_{y} \frac{v_{y 2}[1-(\delta / \alpha)]}{1-\delta\left(1-v_{y 2}\right)-\delta^{2} v_{y 2}}\right\} .
$$

Substituting (10) and (6) in (4), we get

$$
\pi \leq \frac{1-\delta}{\delta v_{y 2}} .
$$

Equation (11) defines the highest inflation rate consistent with the two-generation equilibrium. (Substitution of [11] in [7] confirms that it is above $\pi_{o}$.) Note that this rate is also exactly equal to $\pi_{y}$, the inflation at which the young buyers pay their whole monetary wealth for the red good. In fact, equations (6), (1), and (2) imply

$$
p_{y 2}=\min \left\{I_{y}, I_{y} \frac{\left(1-\delta v_{n 2}\right)[1-(\delta / \alpha)]+\left(\delta^{2} / \alpha\right) v_{o 2}}{1-\delta v_{n 2}-\delta^{2} v_{y 2}}\right\},
$$

and simple differentiation shows that the share of wealth that the

\footnotetext{
${ }^{5}$ Note that the result does not depend on the specific utility function we assume. In general, the expected value of the game to the seller in period 3 will be $U^{e}$, and the buyer will need to offer him $\delta U^{e}$ in period 2. But the optimality of the two-generation regime requires $I_{v o}=I_{o} / \alpha \leq \delta U^{e}$ and the old buyer in period 2 will be left with $\max \left[0,\left(I_{o} / \alpha\right)-\delta U^{e}\right]=0$. The result is more general: in any regime, the price the sellers quote to the oldest generation of buyers with whom they trade must equal their whole monetary wealth.
} 
seller receives increases with inflation, reaching one when inflation reaches

$$
\pi_{y}=\frac{1-\delta}{\delta v_{y 2}}
$$

In summary, the two-generation regime is an equilibrium if the inflation rate is above the rate at which the old buyers trade their entire money holdings for the red good $\left(\pi_{o}\right)$ but below the rate at which this is true for the young buyers. Equations (7) and (13) define $\pi_{o}$ and $\pi_{y}$. Within this regime, there is a perfect equilibrium such that the red good is sold in the first period of negotiations, and its real price depends on the type of buyer being addressed by the seller. Specifically,

$$
p_{o 2}=I_{o}
$$

and

$$
p_{y 2}=I_{y} \frac{\left(1-\delta v_{n 2}\right)[1-(\delta / \alpha)]+\left(\delta^{2} / \alpha\right) v_{o 2}}{1-\delta v_{n 2}-\delta^{2} v_{y 2}}
$$

\section{Bargaining Equilibrium: The One-Generation Regime}

The derivation of the equilibrium price when it is optimal for the seller to address only young customers follows exactly the methodology described above.

The price, as already mentioned, is given by equation (9):

$$
p_{y 1}=\min \left[I_{y}, I_{y}\left(1-\frac{\delta}{\alpha}\right)+\delta^{2} x_{1}\right]
$$

where

$$
x_{1}=v_{y 1} p_{y 1}+\left(1-v_{y 1}\right) \delta x_{1} .
$$

Notice, however, that the probability that at least one young customer will enter the store is now $v_{y 1}$ : since the regime has changed, so has the velocity of circulation of buyers in the market and therefore the probability laws describing meetings between buyers and sellers. We derive these probabilities below.

For equations $(9)$ and $\left(8^{\prime}\right)$ to characterize an equilibrium, we re-

\footnotetext{
${ }^{6}$ Another line of reasoning that leads to the same conclusion is that at the inflation rate at which the seller is indifferent between addressing both young and old buyers and only young buyers, $p_{o 2}=I_{o}=\delta x_{1}$ and $x_{1}=x_{2}$. Substituting these two conditions in eq. (2) for $i=y$, we obtain $p_{y 2}=I_{y}$ at the critical rate.
} 
quire that, given that everybody is selling only to the young, there be no incentive to deviate:

$$
p_{o 1} \leq \delta x_{1}
$$

Again, the old buyers would be willing to trade all their money for the red good, implying

$$
I_{o} \leq \delta x_{1}
$$

Substitution of (16) in (9) leads to

$$
p_{y 1}=I_{y} \text {. }
$$

But equations (9) and $\left(8^{\prime}\right)$ can be solved explicitly:

$$
p_{y 1}=\min \left\{I_{y}, I_{y} \frac{[1-(\delta / \alpha)]\left[1-\delta\left(1-v_{y 1}\right)\right]}{1-\delta\left(1-v_{y 1}\right)-\delta^{2} v_{y 1}}\right\},
$$

and therefore equation (17) is equivalent to

$$
\pi \geq \frac{1-\delta}{\delta v_{y 1}} \text {. }
$$

The conclusion is that it is optimal for the sellers to trade with only young customers whenever condition (19) is satisfied. For such inflation rates, the young buyers will have to exchange their whole wealth for the red good.

If the probabilities of meeting different types of customers did not change across regimes, equations (11) and (19) would define a specific inflation rate at which the sellers stop considering the old buyers as suitable bargaining partners. Since this is not true, the probabilities have to be solved explicitly before anything can be said about the transition from one regime to the next. In addition, a complete solution of the model needs to reconcile the inflation rate with its fundamental cause, the intervention of the bank.

\section{The Matching Process ${ }^{7}$}

Let us call $\theta_{0}$ the ratio of blue to red consumers born each period, $\theta_{0}=n_{b} / n_{r}$, where we assume that $n_{b}$ and $n_{r}$ are large. Let $N_{r}$ be the number of red sellers that are active in the market each period, and notice that $N_{r}$ exceeds $n_{r}$ whenever some red sellers have been unable to complete a transaction in the past.

In the one-generation regime, the only buyers searching in the red

\footnotetext{
${ }^{7}$ A similar matching technology, embedding the Rubinstein game in a multiagent market, has been studied by Binmore and Herrero (1988). It was first proposed by Butters (1977) in a different context.
} 
market are the young; hence exactly $n_{b}$ buyers are active. Under the assumption that each buyer chooses which seller to visit independently of the other buyers, the probability that a particular seller is visited by no customers is $\left[\left(N_{r}-1\right) / N_{r}\right]^{n_{b}}$, which represents the chances that all $n_{b}$ buyers go to one of the other $N_{r}-1$ stores. We may rewrite this as

$$
\left(1-\frac{1}{N_{r}}\right)^{n_{b}}=\exp \left[n_{b} \log \left(1-\frac{1}{N_{r}}\right)\right] \approx e^{-\theta},
$$

where $\theta$ is defined to be $n_{b} / N_{r}$, and the approximation is valid to order $\left(1 / N_{r}\right){ }^{8}$ Therefore, the probability that a red seller meets a suitable buyer is

$$
v_{y 1}=1-e^{-\theta} \text {. }
$$

In a steady state, the number of red sellers born each period must just balance the number of sellers who successfully complete a transaction and exit:

$$
n_{r}=\left(1-e^{-\theta}\right) N_{r}{ }^{9}
$$

Dividing equation (21) by $n_{b}$ and rearranging, we obtain

$$
\theta=\left(1-e^{-\theta}\right) \theta_{0} \text {. }
$$

To guarantee the existence of a steady state, we require $\theta_{0}>1$ : the number of blue consumers being born must be larger than the number of red consumers. In any period, the blue buyers leave the red market for one of two reasons: either they have concluded their transaction, in which case their exit is matched by an equal number of departing sellers, or they have by now become "too poor." This second motivation has no parallel for the sellers, and therefore, for any positive inflation rate, they always leave the red market in smaller numbers than the blue buyers. If the cohorts being born were of equal size, the red market would eventually disappear.

In the two-generation regime, at any time there are two types of buyers searching in the red market: young and old. Each seller prefers to trade with the young customers, and the probability of meeting at least one of them is

$$
v_{y 2}=1-e^{-\theta_{1}}
$$

where $\theta_{1} \equiv n_{b} / N_{r}$ and replaces the earlier $\theta$, while $v_{y 2}$ replaces the

${ }^{8}$ See Feller (1972, pp. 88-92) or David and Barton (1962, chap. 14). Since $N_{r}$ and $N_{b}$ are large, the fraction of sellers without a buyer is the same (to order $1 / N_{r}$ ) each period, even though the fate of any particular seller remains uncertain.

${ }^{9}$ Notice that eq. (21) is derived under the equilibrium condition that all buyer-seller pairs conclude their bargain successfully in the first period and exit the market. 
earlier $v_{y 1} ; N_{r}$ continues to denote the number of red sellers active in the market.

The probability that a seller does not meet any young but meets at least one old customer is

$$
v_{o 2}=e^{-\theta_{1}}\left(1-e^{-\theta_{2}}\right),
$$

where $\theta_{2}$ is the number of old buyers in the market divided by $N_{r}$, and the number of old buyers in the market, which we denote by $N_{b o}$, equals the number of previously unsuccessful young:

$$
N_{b o}=n_{b}-\left(1-e^{-\theta_{1}}\right) N_{r} .
$$

Dividing (25) by $N_{r}$, we get

$$
\theta_{2}=\theta_{1}-1+e^{-\theta_{1}} .
$$

The steady-state flow condition in the two-generation regime is

$$
n_{r}=N_{r}-N_{r} e^{-\theta_{2}} e^{-\theta_{1}},
$$

which says that the number of red sellers born equals the number who meet a suitable customer and exit the market (notice that $N_{r} e^{-\theta_{2}} e^{-\theta_{1}}$ is the number of unsuccessful sellers). Dividing equation (27) by $n_{b}$, substituting for $\theta_{2}$ from equation (26), and rearranging yields

$$
\theta_{1}=\theta_{0}-\theta_{0} e^{1-2 \theta_{1}} \exp \left(-e^{-\theta_{1}}\right) \text {. }
$$

The existence of a steady state again requires $\theta_{0}>1\left(n_{b}>n_{r}\right)$.

Comparing equations (22) and (28), for given $\theta_{0}$, we find that $\theta_{1}>\theta$ or, substituting this result in equations (20) and (23), $v_{y 1}<v_{y 2}$. For a seller, the probability of trading with a young buyer is higher in the two- than in the one-generation regime. Intuitively, at lower inflation rates, sellers are less "difficult" in their choice of bargaining partners, and therefore more sellers leave the market each period, leading to a higher ratio of young buyers to sellers.

\section{The Rate of Price Inflation}

Each period, the bank in our economy creates inflation by printing new money or, more specifically, by multiplying by $\alpha_{0}$ the money holdings of the blue consumers who are going to the red market.

The rate of price increase cannot in general be $\alpha_{0}$ since the latter is the factor by which only a fraction of the money in the economy is multiplied. How large this fraction is, and therefore how large an effect the bank exerts on the price level, clearly depends on the velocity at which the consumers, and the money, circulate in the two markets. The implication is that the relationship between $\alpha_{0}$ and the inflation rate will be different in the different regimes. 
The nominal price of the blue good is derived by the condition stating that the total revenues from its sale must equal the total amount of money spent in the blue market.

Consider, first, the case in which blue buyers are allowed only one period of search: the one-generation regime. In period $t+2$, successful blue consumers born in period $t$ return to the blue market, along with the red sellers with whom they have traded; net money holdings of these two groups are $\left(\alpha_{0} p_{b t}\right)$ (number of successful blue). Recall that $v_{y 1}$ is the fraction of red sellers who successfully match with blue buyers and that $\theta$ is the ratio of blue born (and searching) to red. Then the number of successful blue is just $\left(v_{y 1} / \theta\right) n_{b}$. In addition to these two groups, unsuccessful blue agents born in period $t$ also return to the blue market at time $t+2$; their net money holdings are $\left(\alpha_{0} p_{b t}\right)$ (number of unsuccessful blue), which equals $\left(\alpha_{0} p_{b t}\right)[1-$ $\left.\left(v_{y 1} / \theta\right)\right] n_{b}$. No other buyers shop in the blue market in period $t+2$; hence the equilibrium condition equating nominal supply and demand is

$$
n_{b} p_{b t+2}=\alpha_{0} p_{b t}\left(\frac{v_{y 1}}{\theta}\right) n_{b}+\alpha_{0} p_{b t}\left(1-\frac{v_{y 1}}{\theta}\right) n_{b} .
$$

Simplifying, we get $p_{b t+2}=\alpha_{0} p_{b t}$ or

$$
\alpha^{2}=\alpha_{0}
$$

Equation (29) could have been derived directly by noticing that in this regime, for each dollar that leaves the blue market at $t, \alpha_{0}$ must come back at $t+2$, regardless of how many transactions have been successful in the red market.

In the two-generation regime, the procedure is identical. The buyers of the blue good at time $t+2$ are the blue consumers who, born at $t$, have been successful in their first search, and their red partners; the blue consumers who, born at $t-1$, have been successful in their second search, and their red partners; and the unsuccessful blue agents born at $t-1$. The sum of their money holdings is given by

$$
\alpha_{0} p_{b t}\left(\frac{v_{y 2}}{\theta_{y}}\right) n_{b}+\alpha_{0} p_{b t-1}\left(\frac{v_{o 2}}{\theta_{y}}\right) n_{b}+\alpha_{0} p_{b t-1}\left(1-\frac{v_{y 2}}{\theta_{y}}-\frac{v_{o 2}}{\theta_{y}}\right) n_{b},
$$

which leads to the equilibrium condition

$$
p_{b t+2}=\alpha_{0} p_{b t}\left(\frac{v_{y 2}}{\theta_{y}}\right)+\alpha_{0} p_{b t-1}\left(1-\frac{v_{y 2}}{\theta_{y}}\right)
$$

or

$$
\alpha^{3}=\alpha_{0} \alpha\left(\frac{v_{y 2}}{\theta_{y}}\right)+\alpha_{0}\left(1-\frac{v_{y 2}}{\theta_{y}}\right)
$$


We conclude this discussion with two observations. First, nominal prices in the red market also rise at the rate $\alpha$, as can be seen by comparing buyers in periods $t$ and $t+1$ : young buyers in $t+1$ hold $\alpha$ times as much money as young in $t$, second-generation buyers in $t+1$ hold $\alpha$ times what second-generation buyers hold in $t$, and so forth.

Second, as inflation rises and search is reduced, the velocity of circulation of money increases since blue buyers wait less time before spending their cash balances. It can be shown that a given percentage increase in the money holdings of the blue consumers $\left(\alpha_{0}\right)$ has a larger effect on inflation in the one-generation regime than it does in the two-generation case. (As will become clear below, this property holds generally, for any $[k-1]$ - and $k$-generation regimes.) Note that this result, one of the classical assumptions of all hyperinflation models, is here derived endogenously, as transactions respond to inflation. Of course, within each regime, the velocity of circulation of money is constant, as is the amount of real money in the economy.

\section{Transition from the Two-Generation to the One-Generation Regime}

For given $\delta$ and $\theta_{0}$, the levels of inflation at which the two-generation regime ends and the one-generation regime begins are given by equations (11) and (19):

$$
\pi_{2} \leq \frac{1-\delta}{\delta v_{y 2}}, \pi_{1} \geq \frac{1-\delta}{\delta v_{y 1}} .
$$

Recalling that $\alpha \equiv 1+\pi$, we let $\alpha^{U 2}$ and $\alpha^{L 1}$ denote the points at which these two inequalities become equalities; thus $\alpha^{U 2}$ is the upper edge of the two-generation case and $\alpha^{L 1}$ the lower edge of the onegeneration case. Solution of the matching process has demonstrated that $v_{y 2}$ exceeds $v_{y 1}$, which implies that $\alpha^{U 2}$ is less than $\alpha^{L 1}$. The situation is further complicated, however, by the fact that $\alpha$ depends on $\alpha_{0}$ differently in the two regimes. Letting $\alpha_{1}$ and $\alpha_{2}$ represent $\alpha$ in the one- and two-generation regimes, we have seen that $\alpha_{1}$ exceeds $\alpha_{2}$ for any given $\alpha_{0}$ and that $\alpha_{2}$ depends on $\theta_{0}$, whereas $\alpha_{1}$ does not,

Figure 1 depicts the relationship between $\alpha_{0}$ and $\alpha$ across the two regimes. When $\theta_{0}$ is near one, $v_{y 2}$ is significantly above $v_{y 1}$; as a result, the "probability effect" dominates, and the $\alpha_{0}$ at which $\alpha^{U 2}$ is realized does fall short of the $\alpha_{0}$ at which $\alpha^{L 1}$ is realized. When $\theta_{0}$ is large, however, the seller's chances of meeting a young buyer are high and do not diminish much between the two regimes; hence $v_{y 1}$ and $v_{y 2}$ are similar, and the "velocity effect" that relates $\alpha$ to $\alpha_{0}$ dominates, pushing the $\alpha_{0}$ corresponding to $\alpha^{U 2}$ above the $\alpha_{0}$ corresponding to $\alpha^{L 1}$.

For low $\theta_{0}$, a "mixed-strategy" equilibrium will emerge from $\alpha_{0}$ between point $A$ and point $B$. In this region a fraction $\Omega$ of sellers talk 


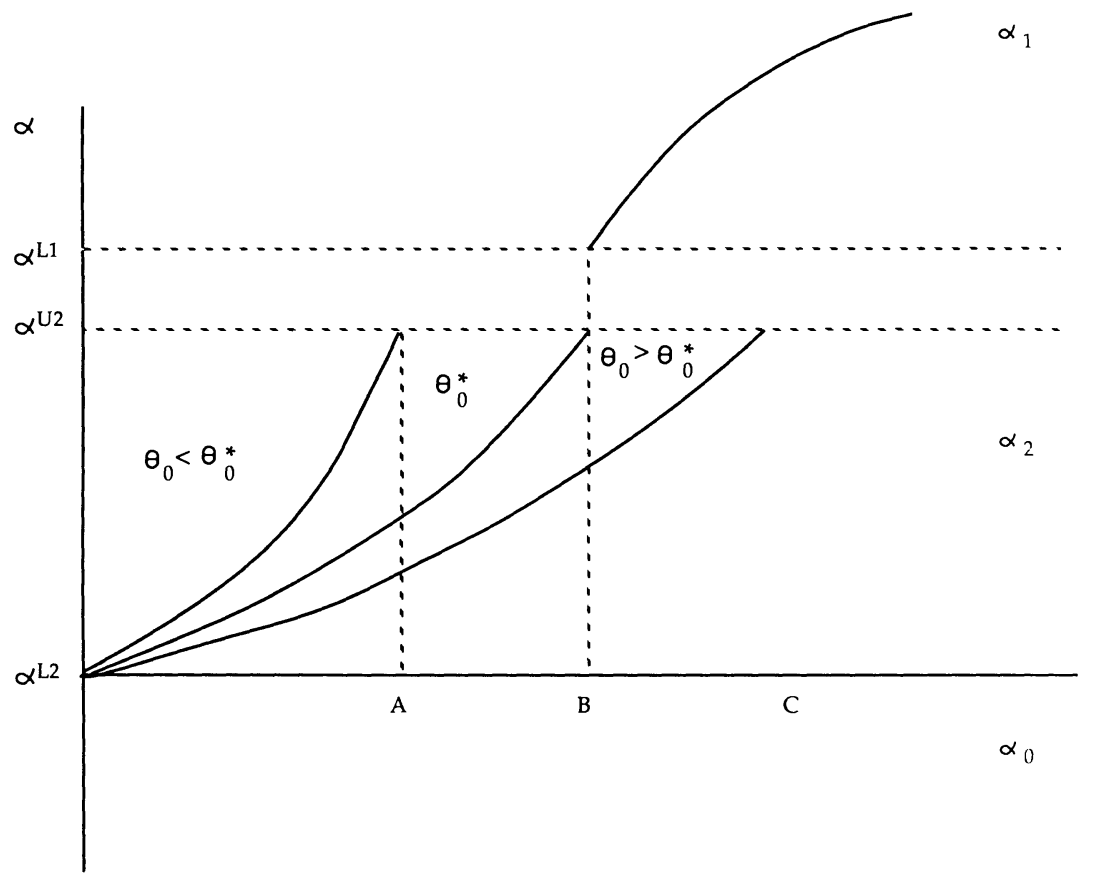

Fig. 1.-Transition between the two- and one-generation regimes

to the young buyers only, and a fraction $1-\Omega$ to both generations. When $\alpha_{0}$ is at the low end of this region, $\Omega$ is near zero, and it increases steadily to one at the upper edge. For each $\alpha_{0}, \Omega$ is such that expected utilities to the two types of sellers are equal. ${ }^{10}$

For high $\theta_{0}$, a "multiple-equilibria" region emerges. For $\alpha_{0}$ between point $B$ and point $C$, there are two possibilities: either all sellers talk to both generations of buyers or all sellers talk to only one generation. Both possibilities are equilibria. If all other sellers talk to both generations, $\alpha$ becomes $\alpha_{2}$, which is less than $\alpha^{U 2}$; hence it is a dominant strategy for a particular seller to talk to both generations as well. If all others talk only to the young, then $\alpha$ becomes $\alpha_{1}$, which exceeds $\alpha^{L 1}$, so that a dominant strategy is to talk to only the young.

Presumably some $\theta_{0}^{*}$ exists at which $\alpha^{U 2}$ equals $\alpha^{L 1}$. We have not

${ }^{10}$ For each $\alpha_{0}$ within the mixed-strategy regime, the fraction $\Omega$ of sellers who talk to both generations is found as the fixed point of the following mappings: each $\Omega$ maps into a seller's probabilities of meeting the young or old buyers; in turn these probabilities map into $\alpha$, prices and expected utilities. If the expected utility of those sellers who talk only to young is, e.g., above the expected utility of those who talk to both generations, $\boldsymbol{\Omega}$ is lowered, but this lowers the probability of meeting a young customer while it raises the probability of meeting an old, causing a readjustment in expected utilities. 
sought to determine this $\theta_{0}^{*}$, but instead have simulated four different values of $\theta_{0}: 1.01,1.10,2.00$, and 10.0 . Of these, 1.01 and 1.10 possess mixed-strategy regions, and 2.00 and 10.0 multiple equilibria.

\section{Expected Utility in the One- and Two-Generation Regimes}

We complete our analysis of the one- and two-generation regimes by calculating the expected utility of the red and blue consumers.

Let us first examine the expected utility at birth of a red seller. Within the two-generation regime, it can be seen directly that it increases with $\alpha$ :

$$
\begin{gathered}
E U_{r 2}=\frac{\delta}{\alpha}\left\{( p _ { y 2 } v _ { y 2 } + p _ { o 2 } v _ { o 2 } ) \left[1+\delta\left(1-v_{y 2}-v_{o 2}\right)\right.\right. \\
\left.\left.+\delta^{2}\left(1-v_{y 2}-v_{o 2}\right)^{2}+\ldots\right]\right\} .
\end{gathered}
$$

The red seller will trade immediately if either a young or an old buyer enters his store, and it will then take him one period to convert his earnings into units of blue good. If he does not trade in the first period - with probability $\left(1-v_{y 2}-v_{o 2}\right)$ - he will have to wait longer; longer still if he is again unlucky in the second period-with probability $\left(1-v_{y 2}-v_{o 2}\right)^{2}$-and so forth. The expected utility converges to

$$
E U_{r 2}=\frac{(\delta / \alpha)\left(p_{y 2} v_{y 2}+p_{o 2} v_{o 2}\right)}{1-\delta\left(1-v_{y 2}-v_{o 2}\right)},
$$

which increases in the bargaining prices.

Similarly, in the mixed-strategy (if one exists) and one-generation regime, the red expected utility equals

$$
E U_{r 1}=\frac{(\delta / \alpha) v_{y 1}\left(\alpha_{0} / \alpha\right)}{1-\delta\left(1-v_{y 1}\right)},
$$

where it should be recalled that $p_{y 1}$ equals $I_{y}$. In the one-generation regime, $E U_{r 1}$ is constant and simplifies to $\delta v_{y 1} /\left[1-\delta\left(1-v_{y 1}\right)\right]$ since $\alpha_{0}$ equals $\alpha^{2}$.

When the two regimes are compared, the two factors working in opposite directions are easily identified. On one hand, $p_{y}$ is higher in the one-generation regime, and this tends to increase $E U_{r 1}$ relative to $E U_{r 2}$. On the other, the probability of successful trade in any period is lower since old buyers are disregarded and the probability of meeting a young blue customer is reduced. This tends to reduce $E U_{r 1}$.

To explore the question of red utility further, we have simulated the economy at the $\theta_{0}$ values of $1.01,1.10,2.00$, and 10.0 , as men- 
tioned above. ${ }^{11}$ Figure 2 illustrates our findings for the representative case $\theta_{0}$ equal to 1.10 and the three $\delta$ values of $.90, .95$, and .99 . In all three cases, the red seller's expected utility is always lower in the onegeneration regime. Connecting the two regimes is a region of mixed strategy, in which the utility declines as the probability $v_{y 1}$ falls.

The result was confirmed in the simulations with the other three $\theta_{0}$ values; since they cover a very wide range, we would suggest that the result is general. For the lower $\theta_{0}$ values, in which the two regimes are connected by a region of mixed strategy, we conclude that, within this region, red expected utility falls with $\alpha_{0}$. For higher $\theta_{0}$, the two regimes overlap in a region of multiple equilibria, and utility depends on which equilibrium emerges. The two-generation equilibrium dominates.

The expected utility of the blue consumers reflects the same ambiguity. The intuition is simple: as the ratio of young buyers to sellers in the market decreases, moving from the two-generation to the onegeneration regime, the probability of purchasing the red good during the first search period rises. This positive effect is, of course, the mirror image of the lower probability of successful trade for the red seller. However, offsetting this is the fact that the real price of the red good becomes higher with inflation.

For a blue buyer, the probability of being chosen as a bargaining

11 'To provide a reference framework, we can calculate the utility of the agents in the case of zero inflation. The first observation is that, in this case, both buyers and sellers leave the market only after a successful transaction, which implies the steady-state conditions $n_{b} / n_{r}=1$ and $N_{b} / N_{r}=1$. For a seller, the probability of having at least one buyer in the first period is $\left(1-e^{-1}\right)$, of having at least one buyer in the second period and none in the first is $e^{-1}\left(1-e^{-1}\right)$, etc. In addition, all buyers in the market are identical, and when two bargaining partners meet, they share the real money holdings of the buyer according to the partition $[1 /(1+\delta), \delta /(1+\delta)]$ (the Rubinstein solution). It is then straightforward to derive

$$
\begin{gathered}
E U_{r}=\frac{\delta\left(1-e^{-1}\right)}{(1+\delta)\left(1-\delta e^{-1}\right)}= \begin{cases}.448 & \text { if } \delta=.9 \\
.473 & \text { if } \delta=.95 \\
.495 & \text { if } \delta=.99\end{cases} \\
E U_{s}=\frac{\delta^{3}\left(1-e^{-1}\right)}{(1+\delta)\left(1-\delta e^{-1}\right)}= \begin{cases}.363 & \text { if } \delta=.9 \\
.427 & \text { if } \delta=.95 \\
.485 & \text { if } \delta=.99\end{cases}
\end{gathered}
$$

As expected, at zero inflation the differences in the utilities of buyers and sellers simply reflect the imposed, and uninteresting, differences in the order and timing of their moves, and disappear as the discount rate goes to one $\left(E U_{r}=E U_{s} \rightarrow .5\right.$ as $\left.\delta \rightarrow 1\right)$. The extra period required by blue consumers to complete their life cycle and the seller's advantage of quoting the first price in the bargaining game account for the $\delta^{2}$ term. This result requires $\theta_{0}=1$ and therefore is not immediately comparable to the values obtained in the simulations (since the presence of inflation requires a higher $\theta_{0}$ ). In general, increasing $\theta_{0}$ favors the sellers and hurts the buyers, by its effect on matching probabilities. 

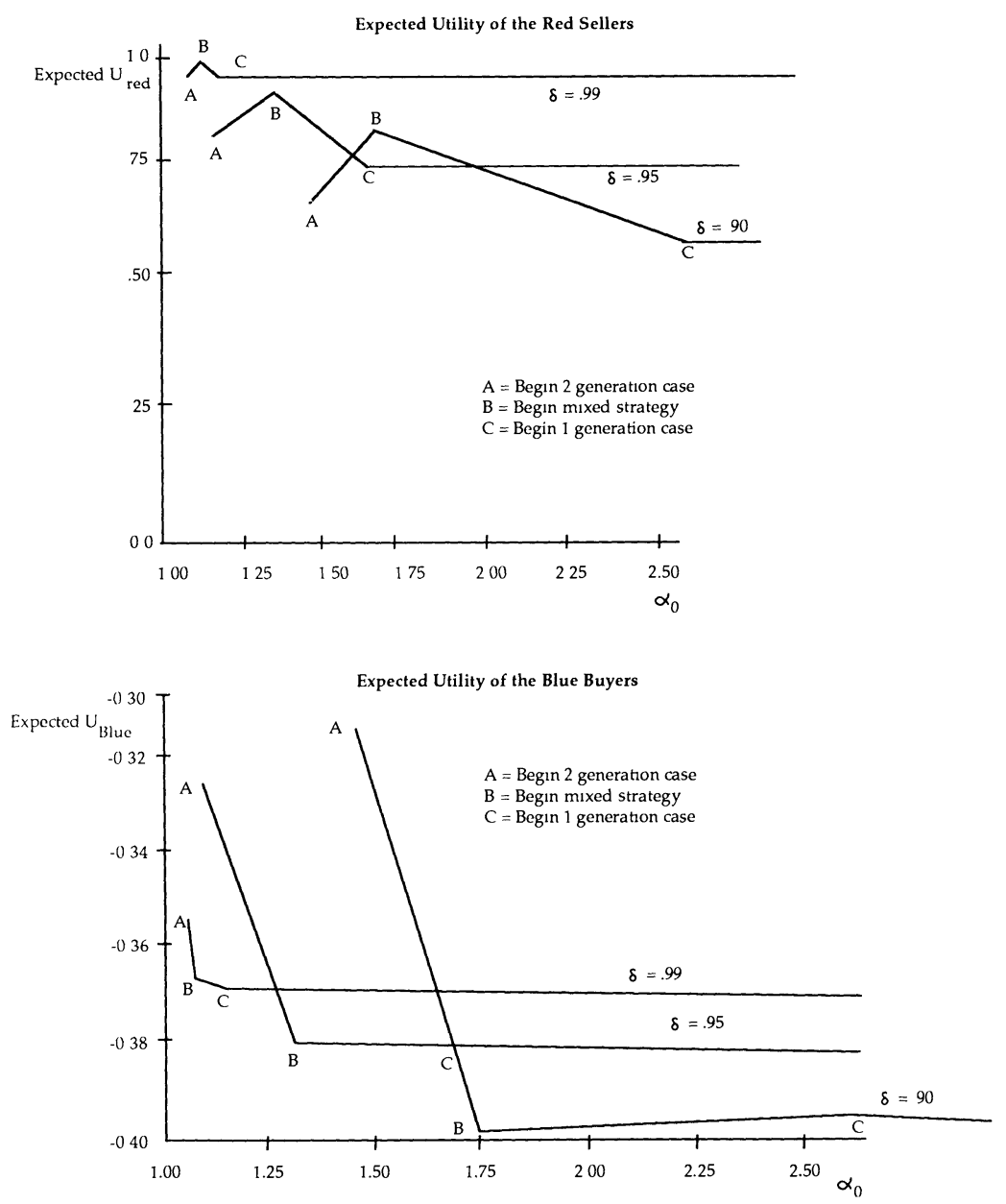

FIG. 2.-Expected utilities across the one- and two-generation regimes

partner is easily derived: it must equal the number of successful buyers of one's generation (identical to the number of red sellers meeting at least one customer of the given age), divided by the overall number of buyers of that generation in the market. That is, the probability of being chosen while belonging to the $i$ th generation in the $k$-generation regime is $v_{i k} / \theta_{l}$. We can immediately verify that while $v_{y 1}<v_{y 2}, v_{y 1} / \theta>v_{y 2} / \theta_{1}$.

Substituting these probabilities in the blue utility function, we get

$$
E U_{b 2}=\frac{v_{y 2}}{\theta_{1}} \frac{\delta^{2}\left(I_{y}-p_{y 2}\right)}{\alpha}+\left(1-\frac{v_{y 2}}{\theta_{1}}-\frac{v_{o 2}}{\theta_{2}}\right)\left(\frac{\delta^{3} I_{o}}{\alpha}-A\right),
$$




$$
E U_{b 1}=\left(1-\frac{v_{y 1}}{\theta}\right)\left(\delta^{2}-A\right)
$$

Let us call $A^{*}$ the minimum value of $A$ that supports the described pure strategy equilibria for the two- and one-generation cases, where a blue agent is allowed the alternative to consume only on the blue market, immediately and without going to the bank $(U=1-A)$. Simulation results (for $\theta_{0}=1.10$ ) indicate that with $A>A *$ and any $\delta$, the expected utility of the blue consumers falls across regimes as inflation increases if $A$ is sufficiently large (i.e., $A>2$ ). In addition, the higher is $\delta$, the closer the critical $A$ is to $A^{*}$, converging to $A^{*}$ for $\delta=.99$, the most relevant case. In other words, if the punishment from not purchasing the red good is high enough, the probability effect does not compensate the blue buyers for the loss in bargaining power deriving from the higher inflation rate. The final result is an overall welfare loss.

\section{Solution of the General Case}

While we have devoted most of our attention to a detailed exposition of the one- and two-generation regimes, our analysis extends to the general case of $k$ generations of buyers. Presumably as $\alpha_{0}$ falls toward one, blue buyers are willing to search more periods in the red market. We would expect the price paid by the youngest buyers in the market, $p_{1 k}$, to fall as $\alpha_{0}$ falls within a regime and also to fall as $k$ rises. In fact, in the limit as $\alpha_{0}$ approaches one and $k$ becomes very large, $p_{1 k}$ should approach the Rubinstein solution. More uncertainty attaches to the behavior of expected utility. For large enough $A$, we expect blue buyers to become better off as $\alpha_{0}$ falls and $k$ rises, but the fate of the red sellers is unclear: lower prices as $\alpha_{0}$ falls will diminish their utility within a regime, but higher probabilities of meeting eligible buyers may increase their utility across regimes, as was found to be true in a comparison of the one- and two-generation regimes.

To derive the equilibrium bargaining prices, we carry over the earlier analysis, with one important modification. In the one- and twogeneration cases, a seller who fails to reach agreement with a buyer by the third period will prefer to wait rather than continue talking to that buyer. By contrast, in the $k$-generation case, a seller who has matched with a buyer of generation $k-2$ or less will be willing to continue talking to that buyer in period 3 since the buyer is no older than $k$ generations. This affects the original bargain because the seller's expected third-period price is changed to reflect the fact that, off equilibrium, he will always have someone to talk to in period 3 .

The equilibrium prices solve $k$ simultaneous equations, each ob- 
tained from a bargaining analysis that matches a representative seller against a buyer of a particular age. Let us define as $x_{2 k}$ the expected price to the seller in the third period, when he has matched with an $i$ th-generation buyer. For $i$ equal to $k$ or $k-1$,

$$
x_{i k}=\frac{\sum_{j=1}^{k} p_{j k} v_{j k}}{1-\delta v_{n k}},
$$

where $v_{n k}=1-v_{1 k}-\ldots-v_{k k}$. For $i$ less than $k-1$,

$$
x_{\imath k}=\sum_{j=1}^{i+1} p_{j k} v_{j k}+\left(1-\sum_{j=1}^{\imath+1} v_{j k}\right) p_{(i+2) k},
$$

where the last term reflects the fact that the seller is always free to rematch with his current partner in period 3 if no one younger arrives. The standard analysis then yields

$$
p_{i k}=\min \left[I_{i}, I_{i}\left(1-\frac{\delta}{\alpha}\right)+\delta^{2} x_{i k}\right], \quad i=1, \ldots, k,
$$

which is a linear simultaneous system in the $p_{i k}$ 's.

The $k$ th regime is an equilibrium for all $\alpha_{0}$ and $\alpha_{k}$ such that (i) at the lower boundary $p_{k k} \geq I_{k}$ and (ii) at the upper boundary $p_{(k-1) k} \leq I_{(k-1)}$, a direct analogue of the equilibrium conditions imposed earlier.

We have not been able to characterize the solution to (37) as completely as its specific one- and two-generation versions. We suspect, however, that within a regime all prices are nondecreasing in $\alpha$ (and $\alpha_{0}$ ) and that the younger a buyer is when he matches, the higher his utility - the "returns to search" result.

The matching probabilities can be readily derived by extending the logic applied to the one- and two-generation regimes. Continue to let $N_{r}$ denote the number of active sellers and $\theta_{1}$ the ratio of young buyers to $N_{r}\left(\theta_{1} \equiv n_{b} / N_{r}\right)$. It is not hard to show that $\theta_{j}$, the ratio of buyers of the $j$ th generation to $N_{r}$, and $v_{j k}$, the probability that a seller talks to a $j$ th-generation buyer, satisfy the following recursive relationships:

$$
\begin{gathered}
\theta_{j+1}=\theta_{j}-v_{j k}, \\
v_{(j+1) k}=\frac{v_{j k} e^{-\theta_{j}}\left(1-e^{-\theta_{j+1}}\right)}{1-e^{-\theta_{j}}}
\end{gathered}
$$

and that the steady-state flow condition equating entry and exit of red sellers is given by

$$
n_{r}=N_{r}-N_{r}\left[\exp \left(-\sum_{j=1}^{k} \theta_{j}\right)\right]
$$


or, if we divide by $n_{b}$ and rearrange,

$$
\theta_{1}=\theta_{0}-\theta_{0}\left[\exp \left(-\sum_{j=1}^{k} \theta_{j}\right)\right] \text {. }
$$

To solve for the $\theta$ 's and $v$ 's, we can substitute from (38) and (39) into (41).

By extending previous results, we can also derive the relationship between $\alpha_{k}$ (inflation in the $k$ th regime) and $\alpha_{0}$. Aggregate money holdings in the blue market in period $t+k$ are

$$
\begin{gathered}
\alpha_{0} p_{b t+k-2}\left(\frac{v_{1 k}}{\theta_{k}}\right) n_{b}+\alpha_{0} p_{b t+k-3}\left(\frac{v_{2 k}}{\theta_{k}}\right) n_{b}+\ldots \\
+\alpha_{0} p_{b t-1}\left(\frac{v_{k k}}{\theta_{k}}\right) n_{b}+\alpha_{0} p_{b t-1}\left(1-\sum_{i=1}^{k} \frac{v_{i k}}{\theta_{k}}\right),
\end{gathered}
$$

where $v_{i k}$ is the fraction of red sellers who, in the $k$-generation regime, successfully match with blue buyers of the $i$ th generation. Equating nominal supply of and demand for the blue good, we obtain

$$
\alpha^{k}=\alpha^{k-2} \alpha_{0}\left(\frac{v_{1 k}}{\theta_{k}}\right)+\alpha^{k-3} \alpha_{0}\left(\frac{v_{2 k}}{\theta_{k}}\right)+\ldots+\alpha_{0}\left(1-\sum_{i=1}^{k} \frac{v_{i k}}{\theta_{k}}\right)
$$

The generalized versions of the expected utilities follow directly from the previous section:

$$
\begin{gathered}
E U_{r k}=\frac{(\delta / \alpha) \sum_{i=1}^{k} p_{i k} v_{i k}}{1-\delta\left(1-\sum_{i=1}^{k} v_{i k}\right)}, \\
E U_{b k}=\sum_{i=1}^{k-1} \frac{v_{i k}}{\theta_{k}} \frac{\delta^{i+1}\left(I_{i}-p_{i k}\right)}{\alpha}+\left(1-\sum_{i=1}^{k} \frac{v_{i k}}{\theta_{k}}\right)\left(\frac{\delta^{k+1} I_{k}}{\alpha}-A\right) .
\end{gathered}
$$

We have simulated our economy with the four $\theta_{0}$ values $1.01,1.10$, 2.00, and 10.0 discussed earlier to cover lower $\alpha_{0}$ and higher $k$ values. One important result has emerged: the red seller's expected utility has an interior maximum at a value of $k$ between two and eight (depending on $\theta_{0}$, and higher for lower $\theta_{0}$ ). That is, there is a range of inflation rates that maximizes the red seller's welfare (see fig. 3).

\section{Conclusions}

This paper examines distributional effects and welfare costs of inflation by focusing on the organization of exchange. More specifically, 


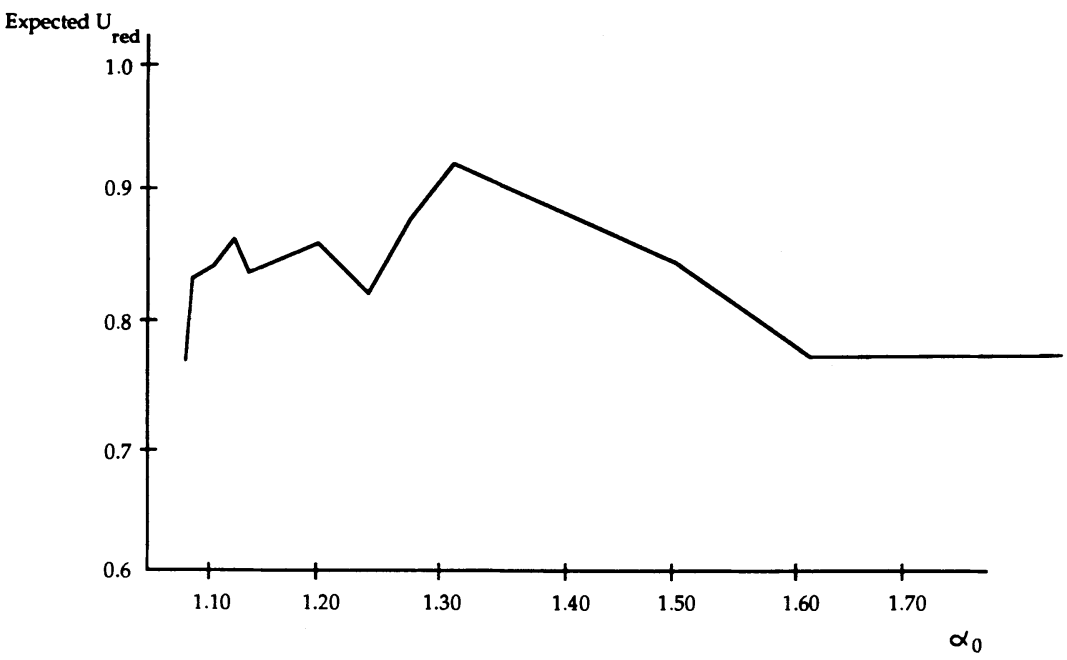

FIG. 3.-Expected utility of the red sellers across many generations $\left(\theta_{0}=1.10, \delta=.95\right)$

we concentrate on the different bargaining powers associated with different roles in transactions, and by emphasizing the importance of time, we allow the trading technology to respond to the increase in nominal values.

The framework lends itself to a number of worthwhile extensions.

First of all, the model could be used to study the effect of inflation on the adoption of different trading technologies. Suppose that agents were born with an endowment of labor that could be employed in producing either a blue or a red good. As inflation increases, entry in the decentralized sector would rise, and one-to-one bargaining would become more widespread. However, this would negatively affect the probabilities of sale. The final equilibrium, if one exists, would presumably lead to the conclusion common to much anecdotal evidence that inflation reduces efficiency by decentralizing exchanges.

A second interesting question concerns the optimal switch to a constant-value currency unit. Even if strictly defined barter were excluded (e.g., by variety in production and specific preferences in consumption), still at high inflation there will be strong incentives toward adopting a stable exchange unit: foreign exchange, if available, gold, or a specific good. Suppose that each agent had to sell his endowment through a bargaining game and then to purchase his consumption again through bargaining. Then inflation would play in his favor in the first stage but against him in the second. Whether, and when, the economy would adopt a stable means of exchange would depend on the relative force of these two opposite effects. 
In both these extensions, the government should be allowed a more active role than the one played in this paper.

\section{References}

Bewley, Truman. "The Optimum Quantity of Money." In Models of Monetary Economies, edited by John H. Kareken and Neil Wallace. Minneapolis: Fed. Reserve Bank Minneapolis, 1980.

Binmore, K. G., and Herrero, M. J. "Matching and Bargaining in Dynamic Markets." Rev. Econ. Studies 55 (January 1988): 17-31.

$\rightarrow$ Burmeister, Edwin, and Wall, Kent D. "Kalman Filtering Estimation of Unobserved Rational Expectations with an Application to the German Hyperinflation." J. Econometrics 20 (November 1982): 255-84.

$\longrightarrow \rightarrow-$ "Unobserved Rational Expectations and the German Hyperinflation with Endogenous Money Supply." Internat. Econ. Rev. 28 (February 1987): 15-32.

Butters, Gerard R. "Equilibrium Distributions of Sales and Advertising Prices." Rev. Econ. Studies 44 (October 1977): 465-91.

Cagan, Philip. "The Monetary Dynamics of Hyperinflation." In Studies in the Quantity Theory of Money, edited by Milton Friedman. Chicago: Univ. Chicago Press, 1956.

Casella, Alessandra. "Testing for Rational Bubbles with Exogenous or Endogenous Fundamentals." J. Monetary Econ. 24 (July 1989).

Casella, Alessandra, and Feinstein, Jonathan. "Inflation and the Organization of Exchange." Manuscript. Cambridge: Massachusetts Inst. Tech., 1987.

$\rightarrow$ Christiano, Lawrence J. "Cagan's Model of Hyperinflation under Rational Expectations.” Internat. Econ. Rev. 28 (February 1987): 33-49.

David, F. N., and Barton, D. E. Combinatorial Chance. New York: Hafner, 1962.

$\rightarrow$ Diamond, Peter A. "Aggregate Demand Management in Search Equilibrium." J.P.E. 90 (October 1982): 881-94. 20.

Diamond, Peter A., and Yellin, Joel. "Pricing and the Distribution of Money Holdings in a Search Economy." Working paper. Cambridge: Massachusetts Inst. Tech., 1984.

—. "The Distribution of Inventory Holdings in a Pure Exchange Barter Economy." Econometrica 53 (March 1985): 409-32.

Feldman, Gerald D. Iron and Steel in the German Inflation, 1916-1923. Princeton, N.J.: Princeton Univ. Press, 1977.

. The Great Disorder: A Political and Social History of the German Inflation, 1918-1923. 1989.

Feldman, Gerald D.; Holtfrerich, Carl-Ludwig; Ritter, Gerhard A.; and Witt, Peter-Christian, eds. The Experience of Inflation: International and Comparative Studies. Berlin: De Gruyter, 1984.

Feller, William. An Introduction to Probability Theory and Its Applications. Vol. 1. 4th ed. New York: Wiley, 1972.

$\rightarrow$ Flood, Robert P., and Garber, Peter M. "Market Fundamentals versus PriceLevel Bubbles: The First Tests.” J.P.E. 88 (August 1980): 745-70.

$\rightarrow$ Frenkel, Jacob A. "The Forward Exchange Rate, Expectations, and the Demand for Money: The German Hyperinflation." A.E.R. 67 (September 1977): 653-7.0. 
Friedman, Milton. "The Optimum Quantity of Money." In The Optimum Quantity of Money and Other Essays. Chicago: Aldine, 1969.

Guttmann, William, and Meehan, Patricia. The Great Inflation, Germany 191923. Farnborough, Eng.: Saxon House, 1975.

$\rightarrow$ Jovanovic, Boyan. "Inflation and Welfare in the Steady State." J.P.E. 90 (June 1982): 561-77.

Kunz, Andreas. Civil Servants and the Politics of Inflation in Germany, 19141924. Berlin: De Gruyter, 1986.

$\rightarrow$ Lucas, Robert E., Jr. "Principles of Fiscal and Monetary Policy." J. Monetary Econ. 17 (January 1986): 117-34.

$\rightarrow$ Lucas, Robert E., Jr., and Stokey, Nancy L. "Optimal Fiscal and Monetary Policy in an Economy without Capital." J. Monetary Econ. 12 (July 1983): 55-93.

Moeller, Robert G. German Peasants and Agrarian Politics, 1914-1924: The Rhineland and Westphalia. Chapel Hill: Univ. North Carolina Press, 1986.

$\rightarrow$ Romer, David. "A Simple General Equilibrium Version of the Baumol-Tobin Model.” Q.J.E. 101 (November 1986): 663-85.

$\rightarrow$ Rotemberg, Julio J. "A Monetary Equilibrium Model with Transactions Costs." J.P.E. 92 (February 1984): 40-58.

Rubinstein, Ariel. "Perfect Equilibrium in a Bargaining Model." Econometrica 50 (January 1982): 97-109.

$\rightarrow$ Salemi, Michael K., and Sargent, Thomas J. "The Demand for Money during Hyperinflation under Rational Expectations: II." Internat. Econ. Rev. 20 (October 1979): 741-58.

$\rightarrow$ Sargent, Thomas J., and Wallace, Neil. "Rational Expectations and the Dynamics of Hyperinflation." Internat. Econ. Rev. 14 (June 1973): 328-50.

Sutton, John. "Non-cooperative Bargaining Theory: An Introduction." Rev. Econ. Studies 53 (October 1986): 709-24.

Townsend, Robert M. "Models of Money with Spatially Separated Agents." In Models of Monetary Economies, edited by John H. Kareken and Neil Wallace. Minneapolis: Fed. Reserve Bank Minneapolis, 1980. 